\title{
Der Molekularsiebeffekt bei der Polyacrylamidgel-Elektrophorese als Funktion von Molekülgröße, Gelkonzentration und Gelvernetzung sowie seine Anwendung zur Molekulargewichtsbestimmung
}

\author{
Von W. THORUN
}

Aus der Biocbemischen Abteilung des Max-Planck-Instituts für Psycbiatrie in München (Direktor: Prof. Dr. G. Peters)

(Eingegangen am 16. August 1970)

\begin{abstract}
Die Abhängigkeit der elektrophoretischen Beweglichkeiten von Eigenschaften des wandernden Proteinteilchens (Volumen, Knäuelungszustand) und Eigenschaften des durchwanderten Gels (Gelkonzentration T, Vernetzungsgrad C) wurde untersucht und in empirische Gleichungen gefaßt. Die gefundenen Zusammenhänge erlauben eine schnelle und einfache gelektrophoretische Bestimmung von Molekulargewichten, insbesondere auch bei wasserunlöslichen (Membran-)Proteinen.

Der Einfluß des Vernetzungsgrades $\mathbf{C}$ wird durch einen Vernetzungskoeffizienten $\mathbf{k}_{\mathbf{c}}$ berücksichtigt. Dieser streut bei demselben Vernetzungsgrad in Abhängigkeit von der speziellen Gelpräparation (gleiche Reagenzien, gleiche Polymerisationsbedingungen) und eignet sich somit als Kontrollgröße zur Testung und Verbesserung der Reproduzierbarkeit der Gelherstellung.
\end{abstract}

The molecular sieving effect in polyacrylamide gel electrophoresis as a function of molecular size, gel concentration and gel cross linkage, and its use in the determination of molecular weights

The dependence of the electrophoretic mobility on the properties of the migrating protein molecule (volume, degree of coiling) and the properties of the supporting gel (gel concentration $T$, degree of cross linkage $C$ ) was studied. Several empirical equations were established, which permit a rapid and simple gel-electrophoretic determination of molecular weights, even for water-insoluble (membrane) proteins. As a consequence of the observed influence of the degree of cross linkage $\mathrm{C}$ a so-called cross linkage coefficient $\mathrm{k}_{\mathrm{C}}$ is defined. This quantity is an approximately linear function of the square root of $C$ and may also vary at the same degree of cross linkage depending on the particular gel preparation (same reagents, same polymerisation conditions). Therefore $\mathrm{k}_{\mathrm{C}}$ is a suitable value to control and improve the reproducibility of the preparation of gels.

Die Einführung der Stärkegelelektrophorese durch SMITHIES (1) und der Polyacrylamidgelelektrophorese durch RaYmond (2) sowie Davis und Ornstein (3) bedeutete eine große Bereicherung der biochemischen Methodik. Herkömmliche Trägermaterialien, wie z. B. das Filterpapier bei der klinisch bedeutsamen Serumelektrophorese, dienten vornehmlich als Antikonvektionsmedium und beeinflußten die Trennung kaum im positiven Sinne. Polyacrylamid- und Stärkegele nehmen dagegen am Trennprozess aktiv teil. Der Trennung aufgrund unterschiedlicher Teilchenladungen, dem eigentlichen Prinzip jeder Elektrophorese, überlagert sich eine Trennung aufgrund unterschiedlicher Molekülgrößen. Dieses Unterscheidungsvermögen von Gelen wird als Molekularsiebeffekt ${ }^{1}$ ) bezeichnet.

Es war das Ziel dieser Arbeit, experimentell zu untersuchen, in welchem Ausmaß der Molekularsiebeffekt vom gelartigen Träger und vom penetrierenden Teilchen abhängt. Als Resultat dieser Arbeit kann die elektrophoretische Beweglichkeit jetzt als empirische

1) Die Worte „Siebeffekt, gesiebt, usw....“ sollte man nicht mit den für dieses Phänomen verantwortlichen physikalischen Vorgängen gleichsetzen (aus HEDRICK (4)). mathematische Funktion von Gelkonzentration und Gelvernetzung einerseits und Molekülgröße und Molekülladung andererseits dargestellt werden. Daraus ergeben sich in mehrfacher Hinsicht praktische Konsequenzen. Einmal wird die Bestimmung von Molekulargewichten mittels Polyacrylamidgelelektrophorese routinemäßig möglich, zum anderen lassen sich für schwierige Trennprobleme optimale Trennbedingungen vorausberechnen und dann verwirklichen. Eine genaue Kontrolle der Gelkonzentration und des Vernetzungsgrades verbessert die Reproduzierbarkeit, was eine Standardisierung der Polyacrylamidgelelektrophorese für die klinische Diagnostik erleichtern kann. Verständlicherweise hat sich das wissenschaftliche Interesse gerade auf die Bestimmung von Molekulargewichten von Makromolekülen (Proteine, Nucleinsäuren) mittels Gelelektrophorese konzentriert. Es genügen bereits Mikrogramm-Mengen mehrerer Testsubstanzen in einer ungereinigten biologischen $\mathrm{Zu}-$ bereitung zur simultanen Gewinnung mehrerer Molekulargewichte. Darüber hinaus können Polyacrylamidgele wegen ihrer durchgehenden chemischen Vernetzung mit verschiedendsten Lösungsmitteln durchtränkt 
werden. So haben wir früher in einem Solvens auf Phenolbasis, welches die Proteine entfaltet und auch Membranproteine molekulardispers in Lösung bringt, die Molekulargewichte zweier Eiweißkörper der Myelinmembran des Meerschweinchens näherungsweise gewonnen (5). Unlängst wurden nach demselben Prinzip simultan die Molekulargewichte von 14 Erythrocytenmembranproteinen des Schweins bestimmt (6).

\section{Definitionen}

Die zwei unabhängigen Variablen von Polyacrylamidgelen sind nach HJERTEN (7) folgendermaßen definiert: Die Gesamtmonomerkonzentration $\mathrm{T}$ wird als Gesamteinwaage von Acrylamid plus N,N'-Methylenbisacrylamid in $\mathrm{g}$ pro $100 \mathrm{ml}$ Ausgangslösung angegeben.

Der Vernetzungsgrad $\mathrm{C}$ drückt das Gewichtsverhältnis von Quervernetzer N,N'-Methylenbisacrylamid zu Gesamtacrylamid in $\%$ aus.

Bei roll reaktiven Reagenzien und vollständiger Polymerisation sind die Absolutwerte von $\mathrm{T}$ und $\mathrm{C}$ identisch denen der polymerisierten Gele, andernfalls proportional.

Die elektrophoretische Mobilität $\mathrm{m}\left(\mathrm{cm}^{2} / \mathrm{V} \cdot \mathrm{sec}\right)$ ist definiert als der pro Zeiteinheit $\mathrm{t}(\mathrm{sec})$ und pro Feldstärkeneinheit $\mathrm{H}(\mathrm{V} / \mathrm{cm})$ zurückgelegte Wanderungsweg $d(\mathrm{~cm}): \mathrm{m}=\mathrm{d} / \mathrm{t} \cdot \mathrm{H}$. Bei vergleichenden Mobilitätsmessungen hat es sich eingebürgert, als $\mathrm{MaB}$ für die Mobilitäten entweder die bei gleicher angelegter Feldstärke $\mathrm{H}$ gemessenen Wanderungswege $\mathrm{d}$ direkt anzugeben (einfache Puffersysteme) $(8,9)$ oder die Wanderungswege $\mathrm{d}$ bei diskontinuierlichen Puffersystemen durch Beziehen auf die Wanderung einer Front indirekt als $R_{\mathrm{F}}$-Wert auszudrücken $(4,10)$.

Diese wesentliche experimentelle Vereinfachung ändert nicht die Gültigkeit gewonnener Befunde. Ausführlicheres über die Theorie der Elektrophorese findet man z. B. bei Hannig (11) und Maurer $(12,13)$.

\section{Material und Methoden}

Verwendete Standardproteine (mit Molekulargewicht und Quelle): Trypsin-Inhibitor aus Pankreas (6500, Mann Res. Lab.), Cytochrom C vom Pferd (12400, Boehringer), Lysozym (14500, Sigma), Myoglobin vom Wal (17800, Mann), Trypsin-Inhibitor aus Sojabohne (22600, Mann), Trypsin (23800, Boehringer), Chymotrypsinogen (25000, Mann), Ovalbumin (45000, Mann), Humanpräalbumin (61000, Behring), Albumin vom Rind mit Polymeren ( $\mathrm{n} \cdot 67000$, Armour), Humantransferrin ( 90000 , Behring), Human- $\gamma$-Globulin (160000, Mann), Katalase (236000, Boehringer), Fibrinogen vom Rind (340000, Behring), Apoferritin vom Pferd (480000, Mann) mit einem zweiten unidentifizierten
Protein.

Die Myelinmembranen wurden aus der weißen Substanz von Meerschweinchengehirnen isoliert (14). Sie enthalten Basisches Myelinprotein und Proteolipid-Protein.

Platten der Abmessungen $7 \cdot 7 \cdot 0,3 \mathrm{~cm}$ mit linear ansteigender Gelkonzentration wurden aus zwei Arbeitslösungen a und b polymerisiert, welche jeweils aus haltbaren Ausgangslösungen
bereitet wurden.

Lösung a enthielt $11,76 \mathrm{~g}$ Acrylamid und $0,24 \mathrm{~g}$ N,N'-Methylenbisactylamid ( $\mathrm{T}=12, \mathrm{C}=2), 0,06 \mathrm{ml} \mathrm{N}, \mathrm{N}^{\prime} \mathrm{N}^{\prime}, \mathrm{N}^{\prime}$-Tetramethyläthylendiamin, $0,045 \mathrm{~g}$ trockenes Ammoniumpersulfat, sowie als
Puffersubstanzen $6 \mathrm{ml} 1 \mathrm{~N} \mathrm{HCl}$ und $4,6 \mathrm{~g}$ Tris (pH 8,9) pro $100 \mathrm{~m} l$ (spezifisches Gewicht 1,01 $\mathrm{g} / \mathrm{ml}$ ) (15).

Lösung b enthielt $2,94 \mathrm{~g}$ Acrylamid und $0,06 \mathrm{~g} \mathrm{~N}, \mathrm{~N}^{\prime}$-Methylenbisacrylamid $(T=3, C=2), 16,5 \mathrm{~g}$ Saccharose und die übrigen Inhaltsstoffe wie in Lösung a pro $100 \mathrm{ml}$ (spezifisches Gewicht $1,05 \mathrm{~g} / \mathrm{ml}$ ). Gleiche Volumina der Lösungen $a$ und $b$ wurden in die Kammern eines in Eiswasser stehenden Gradientenmischers pipettiert. Die langsam austropfende Mischlösung (1 Tropfen pro 6 Sek.) wurde über kleine Filterpapierbrücken einer aus Plexiglasteilen montierbaren Küvette zugeleitet, in deren hintere Plexiglaswand vier äquidistante Kapillarspalte eingesägt waren. In diesen Spalten floß die Lösung sanft ins Innere der Küvette, welche in einem Wasserbad von Raumtemperatur stand. Unter diesen Bedingungen schritt die Polymerisation langsam und kontrolliert in Aufwärtsrichtung noch während des Zulaufs der restlichen Mischlösung voran. Polyacrylamidgelgradienten sind auch anders herstellbar $(6,16,17)$ und werden neuerdings kommerziell angeboten ${ }^{2}$ ).

Monomerlösungen mit variablen Vernetzungsgraden $C=0,1$; 0,$2 ; 0,5 ; 1,0 ; 1,5 ; 2,0 ; 3,0 ; 4,0 ; 5,0$ wurden für $\mathrm{T}=6,5$ und $T=10$ aus je zwei Arbeitslösungen von $C=0$ und $C=10$ in den notwendigen Verhältnissen bei $0^{\circ}$ gemischt und glichen in ihrer übrigen Zusammensetzung Lösung a. Nach Entgasung wurden die Lösungen in den 6 getrennten Kammern einer ähnlichen montierbaren Plexiglasküvette zu Gelen polymerisiert.

Die horizontale, aus Polyäthylenteilen geschweißte Elektrophoresekammer war auch gegen die gefährlich ätzenden Phenollösungsmittel inert (18). Nach teilweiser Demontage der Küvetten wurden die in Gelpuffer gelösten Proben auf Filterpapierchen (Schleicher und Schüll 2043 B) aufgesaugt, an die frei gewordenen Startflächen des Gels gesteckt; und etwa 0,9l eines schwach mit Bromphenolblau angefärbten Elektrodenpuffers der Zusammensetzung $0,6 \mathrm{~g}$ Tris und 2,88.g Glycin pro $l$ $(\mathrm{pH} 8,3)(15)$ bis über den oberen Gelrand eingefüllt. Unter der niedrigen Stromstärke von $6 \mathrm{~mA}$ wanderte die Pufferfront in 90 Min. bei $20^{\circ}$ etwa $6 \mathrm{~cm}$, und zwar wegen des gegenläufigen Saccharosegradienten durch alle Gelkonzentrationen gleich schnell.

Bei dem Solvens Phenol-Essigsäure-Wasser $(2: 1: 1, \mathrm{w} / \mathrm{v} / \mathrm{v})$ (19) wurde folgendermaßen modifiziert verfahren: Die Puffersubstanzen in den Lösungen $a$ und $b$ fielen weg. Jeder fertige Gelgradient wurde wenigstens $24 \mathrm{Stdn}$. lang gegen $1 l$ des Solvens äquilibriert und die Quellung als Verhältnis der Gewichte vor und nach der Äquilibrierung gemessen. Zwischen zwei Glasplatten eingelegt wurden die Gele bei $12 \mathrm{~mA}$ etwa $90 \mathrm{Min}$. der Elektrophorese unterworfen.

Die Fixierung und Anfärbung erfolgte in einer filtrierten (!) 1 proz. Lösung von Amidoschwarz $10 \mathrm{~B}$ in 7 proz. Essigsäure. Aus den Photogtaphien der elektrophoretisch entfärbten Gele wurden die Mobilitäten als Wanderungswege oder $R_{\mathrm{F}}$-Werte gemessen. Diese waren in wiederholten Bestimmungen auf wenigstens $\pm 5 \%$ reproduzierbar.

\section{Ergebnisse}

\section{Elektrophoretische Mobilität und Gelkonzen-} tration $T$

Zur Erfassung dieses schon früher an Stärke- $(20,21)$ und Polyacrylamidgelen $(4,5,8,10,22,23)$ studierten Zusammenhangs wurden Platten linear ansteigender Polyacrylamidgelkonzentration polymerisiert und bestimmte Proteintestmischungen quer zu diesen Gelgradienten elektrophoriert. Die Ergebnisse in den Abbildungen 1, 2, 3 machen zwei Tatsachen deutlich. Die Mobilitäten aller Proteine nehmen mit steigender Gelkonzentration ab, das Ausmaß dieser Abnahme ist

2) Gradipore, Townson und Mercer (Distributors) Pty. Ltd., 318 Burns Bay Road, Lane Cove, N. S. W: 2066, Australia. 


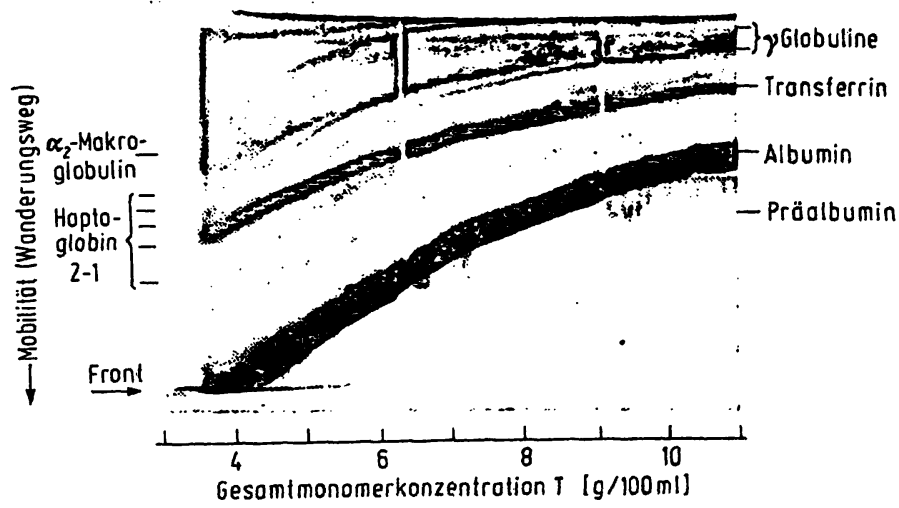

Abb. 1

Die Elektrophorese quer zu einem linearen Polyacrylamidgel-Konzentrationsgradienten zeigt die Abhängigkeit des Bandenmusters von der Gelkonzentration. Vernetzungsgrad $C=2$. Humanserum: Präalbumin, Albumin, Transferrin, a ${ }_{2}-$ Makroglobulin, die Haptoglobin $2-1$ Polymere und die $\gamma$-Globulin-Region sind gekennzeichnet. Für das hochmolekulare $\alpha_{2}-M a k r o g$ lobulin $(M=860000)$ existiert eine Aus-
schlußgrenze von $T=8$ ab. Der Saccharosegradient verlief ebenso schlußgrenze von $T=8$ ab. Der Saccharosegrad

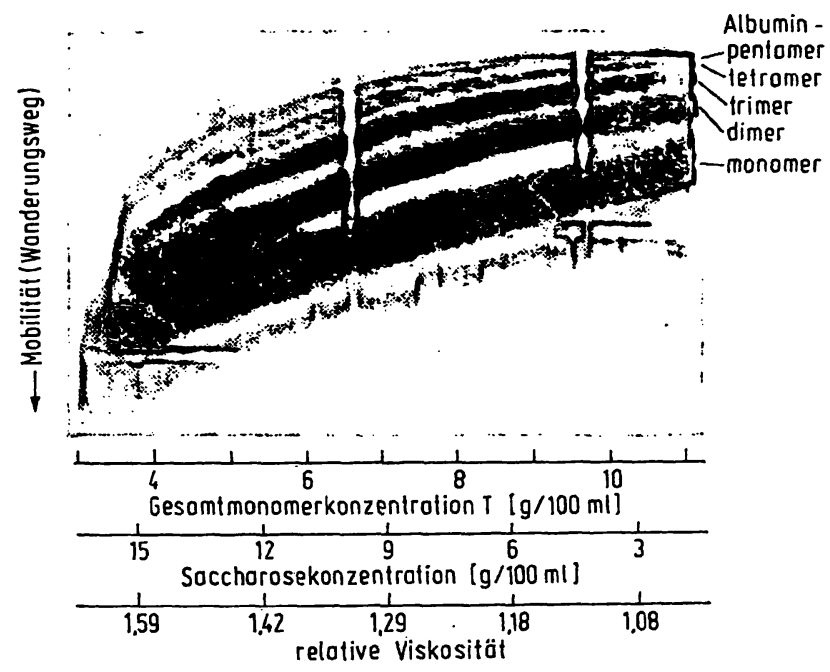

Abb. 2

Elektrophorese von Albuminpolymeren quer zu einem linearen Polyacrylamidgel-Konzentrationsgradienten. Vernetzungsgrad $C=2$. Die regelmäßige Kurvenschar läßt einen allgemeinen Zusammenhang külgröße erahnen (Gleichung (3)). Das diskontinuierliche Puffersystem wich von dem in der Methodik angegebenen ab. Der Gelpuffer enthielt $6 \mathrm{ml} 1 \mathrm{~N} \mathrm{HCl}$ und $0,86 \mathrm{~g}$ Tris pro $100 \mathrm{ml}$ (pH 7,5), der Elektro-
denpuffer $5,52 \mathrm{~g}$ Diäthylbarbitursäure und $1,0 \mathrm{~g}$ Tris pro $l(\mathrm{pH} 7,0)(45)$

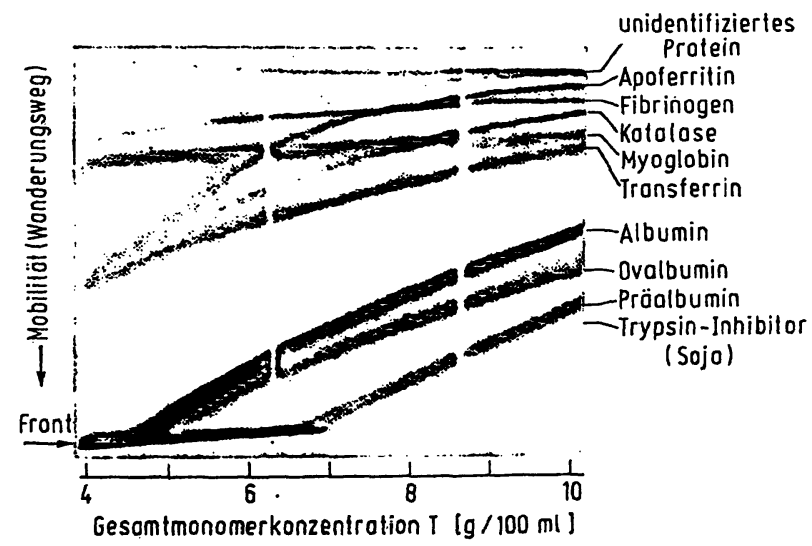

Abb. 3

Elektrophorese eines Testgemisches aus 9 Standardproteinen (s. MeElektrophorese eines Testamidgel-Konzentrationsthoden) quer zu elnem miten unterschiedlichen gradienten. Vern Molekulladungen und für das gen (Gleichung (3)) ruhren zu Un wählen zeichnet. Aus 1. c. (5) jedoch für jedes Teilchen verschieden. Nach FERGUSON (21) und MORRIs (8) läßt sich dieses Verhalten durch die folgende allgemeine Gesetzmäßigkeit beschreiben:

$$
\log m=\log m_{n}-K \cdot T ;
$$

wobei $m$ die Mobilität eines Proteins bei irgendeiner Gelkonzentration $T$ und $m_{0}$ seine freie Mobilität bedeutet. $\mathrm{K}$ ist eine für jedes Protein und jeden Vernetzungsgrad charakteristische Retardationskonstante. Zur Úberprüfung dieser inzwischen von verschiedenen Autoren $(4,8,10,21)$ für richtig befundenen Relation wurden aus den Abbildungen 2 und 3 die Mobilitäten $m$ als Wanderungswege bei allen ganzzahligen Gelkonzentrationen $T$ gemessen und in den Abbildungen 4 und 5 deren dekadische Logarithmen gegen die zugehörigen Gelkonzentrationen aufgetragen. Tatsächlich findet sich der von Gleichung (1) geforderte lineare Zusammenhang zwischen Mobilität $\mathrm{m}$ und Gelkonzentration $\mathrm{T}$ für alle Proteine, ausgenommen das Fibrinogen, bestätigt.

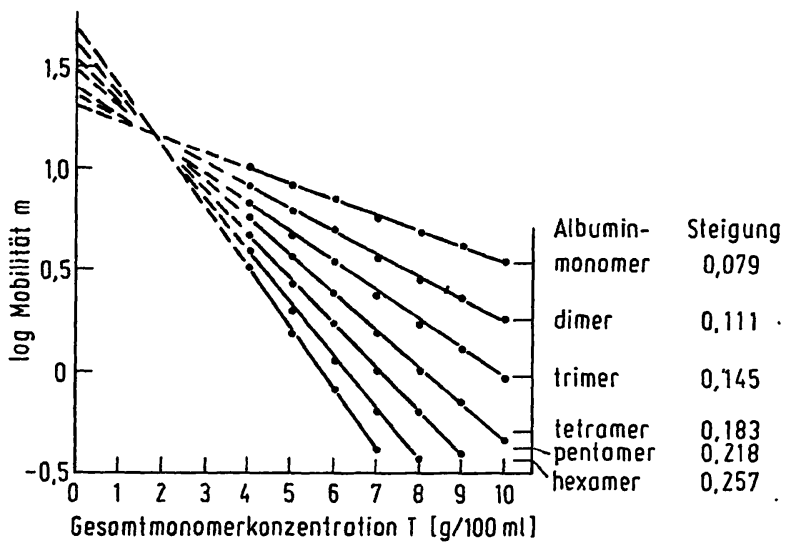

Abb. 4

Linearer Zusammenhang zwischen dem Logarithmus der Mobilitäten und der Gelkonzentration $T$ für Albuminpolymere (Gleichung (1)). Vernetzungsgrad $\mathrm{C}=2$. Die Steigung $\mathrm{K}$ der Geraden nimmt mit jedem Polymer um den gleichen Wert zu (Gleichung (2)). Extrapolation der Linien ergibt für $T=0$ Approximationswerte der freien Mobilitäten. Alle Meßwerte aus Abb. 2. Die Wanderungswege wurden mit den jeweiligen für $20^{\circ}$ gültigen relativen Viskositäten wäßriger Saccharoselösungen korrigiert

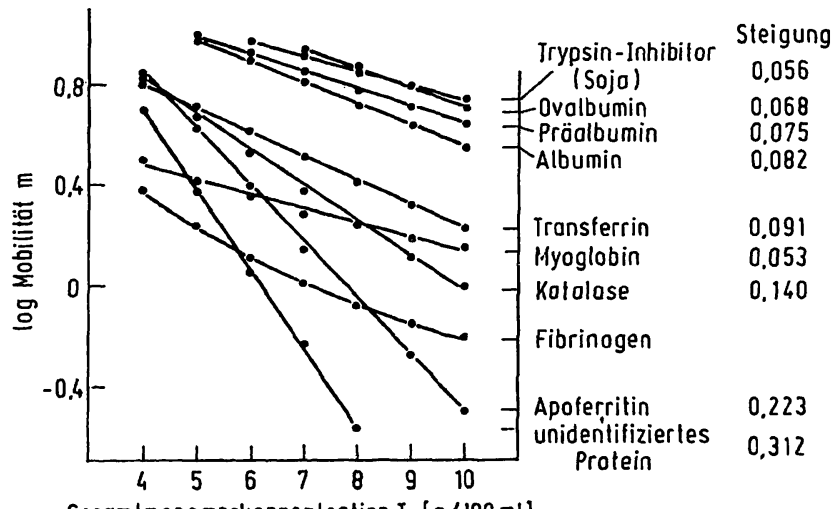

Gesamimonomerkonzenlrotion $T[\mathrm{~g} / 100 \mathrm{ml}]$

Abb. 5

Linearer Zusanmenhang zwischen dem Logarithmus der Mobilitäten und der Gelkonzentration $T$ für verschiedene Standardproteine (s. Methoden) (Gleichung (1)). Vernetzungsgrad $C=2$. Fibrinogen weich von der Linearität $a b$. Die angegebenen Steigungen $K$ der Geraden sind proportional den Molekülgrößen (Gleichung (2)). Alle Meßw stammen aus Abb. 3 und wurden wie in Abb. 4 korrigiert 
Die angegebenen Näherungsgeraden wurden mittels eines Computerprogramms nach der Methode der kleinsten Quadrate berechnet. Die Güte der Linearität wurde für jede Punktfolge durch Berechnung des Pearson'schen Produkt-Moment-Korrelationskoeffizienten $r$ getrennt getestet. Dieser war mit Werten zwischen -0,9999 (Transferrin) und -0,9990 (Albumin-Tetramer) so wenig von $-1,0$ verschieden, $\mathrm{da} \beta$ praktisch perfekte Linearität vorliegt. Für Myoglobin war $r=-0,9953$. Für Fibrinogen mit $r=-0,9883$ erschien dagegen nur die Einzeichnung einer Ausgleichskurve vertretbar (Abb. 5).

Nach Gleichung (1) ist die Steigung jeder Gerade in den Abbildungen 4 und 5 gleich ihrer Retardationskonstanten $\mathrm{K}$, darüber hinaus ist der Ordinatenabschnitt jeder Gerade gleich dem Logarithmus der freien Mobilität $\mathrm{m}_{0}$. Letzteres konnte in diesem Rahmen experimentell nicht geprüft werden. Jedoch fanden FErGuSON (21) und MORrIs (8) für mehrere Proteine gute Übereinstimmung zwischen den durch Verlängerung der Geraden bis $T=0$ extrapolierbaren freien Mobilitäten und den direkt mittels freier Elektrophorese gewonnenen freien Mobilitäten. In Abbildung 4 wurde eine solche Extrapolation der freien Mobilitäten am Beispiel der Albuminpolymeren durchgeführt.

Elektrophoretische Mobilität und Molekülgröße

In Gleichung (1) ist die Molekülladung bereits eliminiert, denn $\mathrm{im} \log \left(\mathrm{m} / \mathrm{m}_{0}\right)$, wo beide Mobilitäten proportional zur Effektivladung sind (24), kürzt sich die Ladung heraus. In der Steigungskonstanten $K$ sollte sich deshalb nicht mehr der Einfluß der Molekülladung, wohl aber der Einfluß der Molekülgröße ausdrücken. In den Abbildungen 4 und 5 sind die errechneten Steigungen notiert. In Abbildung 6 wurden diese Steigungen gegen die Molekulargewichte der Referenzproteine aufgetragen. Es ergibt sich ein linearer $\mathrm{Zu}-$ sammenhang, wie er bereits früher nachgewiesen wurde (4). Abweichungen von der Geraden erklären sich durch mangelhafte Korrelation zwischen Molekülgrößen und Molekulargewichten, wie sie z.B. unterschiedliche Teilchendichten verursachen (s. Diskussion). Es gilt:

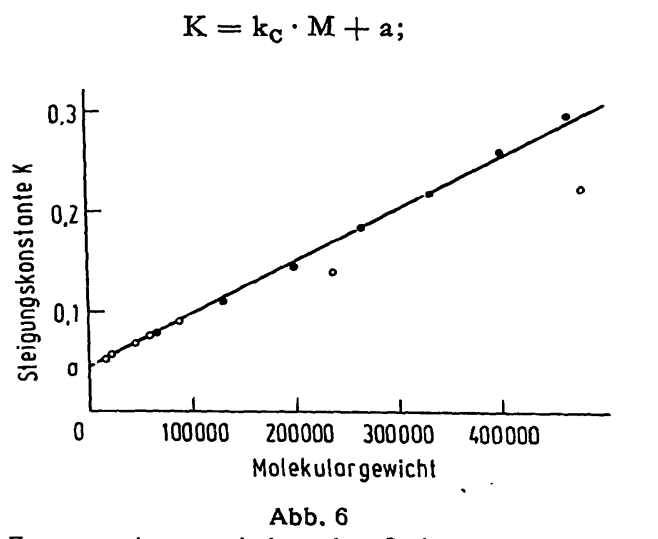

Abb. 6

Linearer Zusammenhang zwischen den Steigungskonstanten $\mathrm{K}$ und den Molekulargewichten (Gleichung (2)). Punkte: Albuminpolymere,
Kreise: Standardproteine aus Abb. 3. Katalase und Apoferritin verKreise: Standardproteine aus Abb. 3. Katalase und
halten sich irregulär (s. Diskussion) wobei $k_{c}$ eine hauptsächlich vom Vernetzungsgrad $C$ abhängige Größe und a eine empirische Konstante ist. Geometrisch gesehen ist $\mathrm{k}_{\mathrm{c}}$ gleich der Steigung der Regressionsgeraden in Abbildung 6, a gleich ihrem durch Extrapolation für $\mathrm{M}=0$ erhaltenen Ordinatenabschnitt, für den sich hier der Wert 0,046 findet. Zusammenfassung der Gleichungen (1), (2) führt zu:

$$
\log \mathrm{m}=\log \mathrm{m}_{0}-\left(\mathrm{k}_{\mathbf{c}} \cdot \mathrm{M}+\mathrm{a}\right) \cdot \mathrm{T} .
$$

Demnach ist die elektrophoretische Beweglichkeit m eines Teilchens im Gel als Funktion der Molekülgröße $M$ und der Molekülladung $Q\left(m_{0}=Q / 6 \pi \mathrm{r} \eta ;\right.$ SтоKEs'sches Gesetz) einerseits, als Funktion der Gelkonzentration $T$ und $\operatorname{der}$ Gelvernetzung $C$ andererseits beschreibbar. Die Viskosität $\eta$ der flüssigen Phase im Gel, also des Puffermediums, geht.über die freie Mobilität $\mathrm{m}_{0}$ in die Gleichung ein. Die Gleichung gilt für kompakte, nicht zu langgestreckte Moleküle mindestens für den ganzen untersuchten Molekulargewichtsbereich von 17800 bis 480000. Andere Experimente (4) bestätigen ihre Gültigkeit mindestens für Molekulargewichte von 50000 bis 500000 . Wird die für alle Gelkonzentrationen gültige Gleichung (3) je einmal für zwei verschiedene Gelkonzentrationen $T_{1}$ und $T_{2}$ $\left(T_{2}>T_{1}\right)$ angesetzt und die eine Gleichung von der anderen subtrahiert, so erhält man die speziellere Gleichung:

(4)

$$
\log \left(m_{1} / m_{2}\right)=\left(k_{c} \cdot M+a\right) \cdot\left(T_{2}-T_{1}\right) .
$$

Hier sind $\mathrm{m}_{1}$ und $\mathrm{m}_{2}$ die als $R_{F}$ oder Wanderungswege gemessenen Mobilitäten bei den zwei verschiedenen Gelkonzentrationen $T_{1}$ und $T_{2}$ und ihr Verhältnis $\mathrm{m}_{1} / \mathrm{m}_{2}$ der Mobilitätenquotient. Diese Größen lassen sich experimentell einfach und schnell gewinnen und sind praktisch anwendbar zur Bestimmung von Molekulargewichten und zur Vorausberechnung optimaler Trennbedingungen. Nach Gleichung (4) ist der Logarithmus des Mobilitätenqusotienten lineat abhängig vom Molekulargewicht. $\mathrm{Da}$ alle hier gefundenen experimentellen Werte mit Gleichung (3) automatisch auch Gleichung (4) gehorchen, wurde die Gültigkeit von Gleichung (4) nochmals isoliert mittels anderer Daten in Abbildung 7

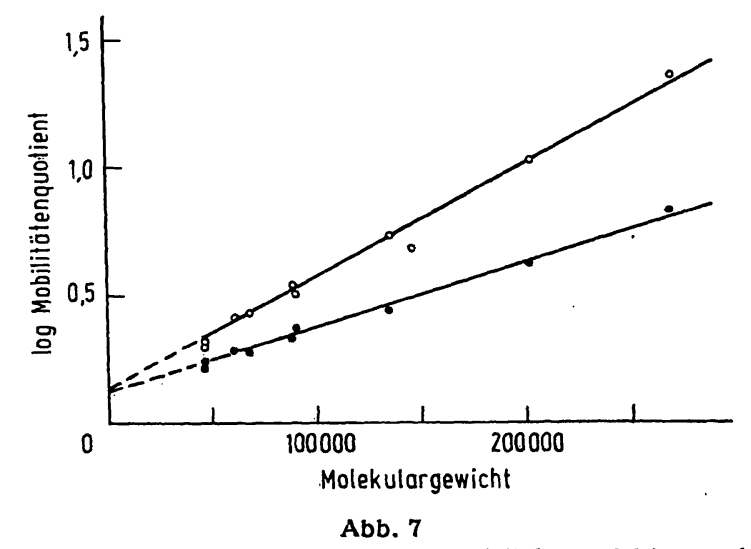

Linearer Zusammenhang zwischen den Molekulargewichten und dem Logarithmus der Quotienten der Mobilitäten bei zwei verschiedenen Gelkonzentrationen (Gleichung (4)). Punkte: 5 proz. u. 8 proz. Gele, Kreise: 5 proz. u. 10 proz. Gele. Die Steigungen der Geraden verhalten sich gemäB Gleichung (4) wie die Differenzen dieser Gelkonzentrationen (3:5). Daten nach ZWAAN(9). Standardproteine mit Molekulargewichten: Ovalbumin $(1+2) 45000$, Humanhämoglobin 64000 , Albuminpolymere vom Rind n .67 .000 , Humantransferrin 88000 , Humanhaptoglobin $1-189000$, Humanlactátdehydrogenase 146000 
nachgewiesen. Es ist in diesem Zusammenhang lehrreich, daran zu exinnern, daß solche Quotienten von Mobilitäten seit einem Vorschlag von ORNSTEIN (24) mehrfach zur empirischen Abschätzung von Molekülgrößen durch Gelelektrophorese Anwendung fanden $(5,6,9,25,26)$.

\section{Elektrophoretische Mobilität und \\ Vernetzungsgrad C}

Der Vernetzungsgrad $\mathrm{C}$ bestimmt makroskopisch die Formbeständigkeit und Elastizität eines Gels. Darüber hinaus beeinflußt er aber auch wesentlich die elektrophoretischen Beweglichkeiten, worauf zunehmend hingewiesen wird $(4,8,27,28,29)$. Abbildung 8

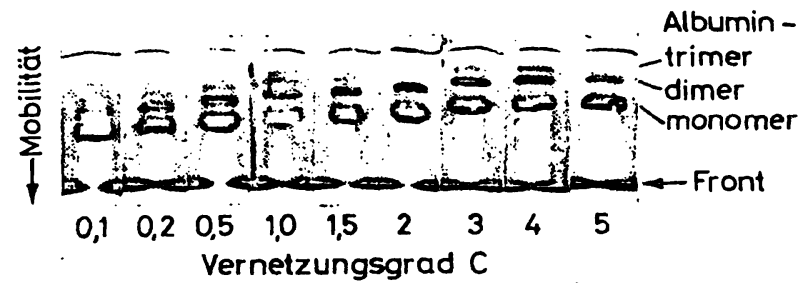

[\% Quervernetzer vom Gesamtacryiamid]

Abb. 8

Mobilitäten der Albuminpolymeren bei verschiedenen Vernetzungsgraden, aber konstanter Gelkonzentration $(T=10)$. Selbst bei dem extrem niederen Vernetzungsgrad $C=0,1$ werden die Polymere noch deutlich gesiebt. Die Albumine sind durch ihre Affinität zu Brom deutlich gesiebt. Die Albumine sind durch ihre Affinitat zu Bromein Auseinanderfließen der weniger vernetzten Gele durch Vermeiden der üblichen Färbeprozedur verhindert.

zeigt in einer Versuchsreihe mit Albuminpolymeren, $\mathrm{da} \beta$ sich trotz gleichbleibender Gelkonzentration bei Erhöhung des Vernetzungsgrades von $C=0,1$ bis $\mathrm{C}=5$ hinauf die Mobilitäten erheblich vermindern, und zwar nicht proportional. Vergleicht man z. B. die Albumine bei $\mathrm{C}=4$ gegenüber $\mathrm{C}=0,1$, so ist in diesem Falle $(\mathrm{T}=10)$ die Mobilität des Monomer auf $67 \%$, die des Dimer auf 53\% und die des Trimer schon auf $42 \%$ gesunken. Es erscheint, als würde der Siebeffekt des Gels bei Erhöhung des Vernetzungsgrades, ähnlich wie bei Erhöhung der Gelkonzentration, um einen Faktor multipliziert. Vergleichbare Befunde erhielten FAwCETT und MORRIs (27) bei Gelchromatographien mit verschieden stark vernetzten Gelkörnchen. Nach einer von HeDrICK und SMITH (4) gemachten Beobachtung vergrößern sich die Steigungen der Diagramme von $\log \mathrm{m}$ gegen $\mathrm{T}$ (Abb. 4,5), wenn man den Vernetzungsgrad C erhöht. Diesem Effekt trägt der Faktor $k_{c}$ in Gleichung (2), (3), (4) Rechnung. $\mathrm{k}_{\mathrm{G}}$ ist eine hauptsächlich vom Vernetzungsgrad abhängige Materialkonstante, für die der Terminus Vernetzungskoeffizient geeignet erscheint. Der Vernetzungskoeffizient $\mathrm{k}_{\mathrm{c}}$ läßt sich nach Gleichung (4) aus dem für mindestens zwei Eichproteine experimentell ermittelten Mobilitätenquotienten berechnen. Aus den Experimenten von $Z$ waAN (9), der mit Cyanogum $(C=5)$ arbeitete, ergibt sich so: $k_{C=5}=9,1 \cdot 10^{-7}$. Analog errechnet sich für diese Arbeit $(C=2): k_{C=2}=5,2 \cdot 10^{-7}$. Diese Werte gelten für die Verwendung dekadischer Logarithmen und für Gele, die in ungequollenem Zustand

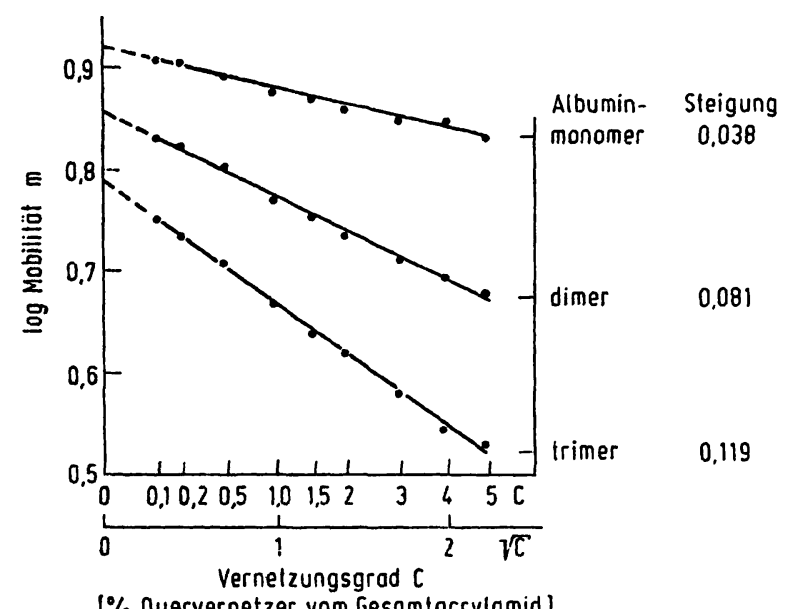

$[\%$ Quervernetzer vom Gesomtocrylomid] bzw. $\sqrt{\mathrm{C}}$

Abb. 9

Linearer Zusammenhang zwischen dem Logarithmus der Mobilitäten und der Wurzel aus dem Vernetzungsgrad $\mathrm{C}$ bei konstanter Gelkonzentration $(T=6,5)$. Die für $C=0$ extrapolierten Näherungswerte der Mobilitäten zeigen, daß die Polymere auch in einer 6,5proz. Polyacrylamidlösung deutlich gesiebt werden (vgl. Abb. 4). Ultrazentrifugationen mit Hyaluronsäure haben diesen Siebeffekt von Lösungen Hochpolymerer bestätigt (46). Jeder eingetragene Ordinatenwert is der Mittelwert aus drei unabhängigen Versuchen, in denen die $R_{F^{-}}$ Werte auf wenigstens $\pm 0,01$ genau reproduzierbar waren

elektrophoriert wurden. Ganz entsprechend lassen sich verschiedendsten Vernetzungsgraden $C$ die zugehörigen Vernetzungskoeffizienten $\mathrm{k}_{\mathrm{c}}$ zuordnen, was letztlich zu einem allgemeinen funktionellen Zusammenhang zwischen beiden Größen führt. Nach Gleichung (3) ist der Logarithmus der Mobilität eine lineare Funktion des Vernetzungskoeffizienten $\mathrm{k}_{\mathrm{c}}$ und damit ein $\mathrm{MaB}$ für $\mathrm{k}_{\mathrm{c}}$. In Abbildung 9 wurden in einer gewissen Analogie zum früheren Vorgehen (vgl. Abb. 4, 5) der Logarithmus der bei verschiedenen Vernetzungsgraden $C$, aber konstanter Gelkonzentration $(\mathrm{T}=6,5)$, als $R_{\mathrm{F}}$-Wert gemessenen Mobilitäten der Albumine diesmal gegen die Wurzel aus dem Vernetzungsgrad C aufgetragen. Der Augenschein und die berechneten Korrelationskoeffizienten $(r=-0,992 ;-0,997$; $-0,998)$ machen eine lineare Abhängigkeit wahrscheinlich, was nahelegt, daß mit dem $\log m$ auch $k_{c}$ eine lineare Funktion der $/ \cdot \bar{C}$ ist, zumindest bei ungequollenen Gelen. Das erarbcitete experimentelle Material ist begrenzt, da die Gele bei der üblichen Färbeprozedur mit sinkendem Vernetzungsgrad zunehmend quellen, was exalste Mobilitätsmessungen erschwert. Ziel sollte es jedoch sein, die Mobilität auch direkt als Funktion des Vernetzungsgrades $C$ beschreibbar zu machen.

Elektrophoretische Mobilität entfalteter Polypeptidketten; Molekulargewichtsbestimmung von Membranproteinen

Abbildung 10 zeigt das Ergebnis einer Elektrophorese in einem Lösungsmittel aus zwei Gewichtsteilen Phenol und je einem Volumenanteil Essigsäure und Wasser (19). Solche und äbnliche Systeme sind fähig, biologische Membranen vollständig in ihre einzelnen Lipoid- und Proteinbestandteile aufzulösen. Sie wurden von uns zur gelelektrophoretischen Analyse von Membranproteinen des Zentralnervensystems verwendet 
$(5,18)$. Wenn nun auch unter so extremen Bedingungen irgendein Zusammenhang zwischen elektrophoretischer Wanderung und Molekülgröße existierte, sollte man dies zur Bestimmung von Molekulargewichten von Membranproteinen nützen können. Wir haben schon früher einen solchen Zusammenhang nachgewiesen (5). Er ist jedoch anders als für wäßrige Systeme. Man erhält nämlich nicht die von Gleichung (4) vorgeschriebene lineare Abhängigkeit zwischen dem Logarithmus des Mobilitätenquotienten und $\mathrm{M}$ (vgl. Abb. 7), wohl aber eine befriedigende lineare Abhängigkeit zwischen dem Logarithmus des Mobilitätenquotienten und der $\sqrt[3]{\mathrm{M}}$, wie in Abbildung 11 gezeigt ist:

$$
\left.\log \left(m_{1} / m_{2}\right)=\text { const } \cdot \sqrt[3]{M}+\text { const }^{3}\right) \text {. }
$$

Acht der neun getesteten Proteine im Molekulargewichtsbereich von 14500 bis 90000 gehorchten dieser Relation auf wenigstens $\pm 10 \%$ genau. Myoglobin

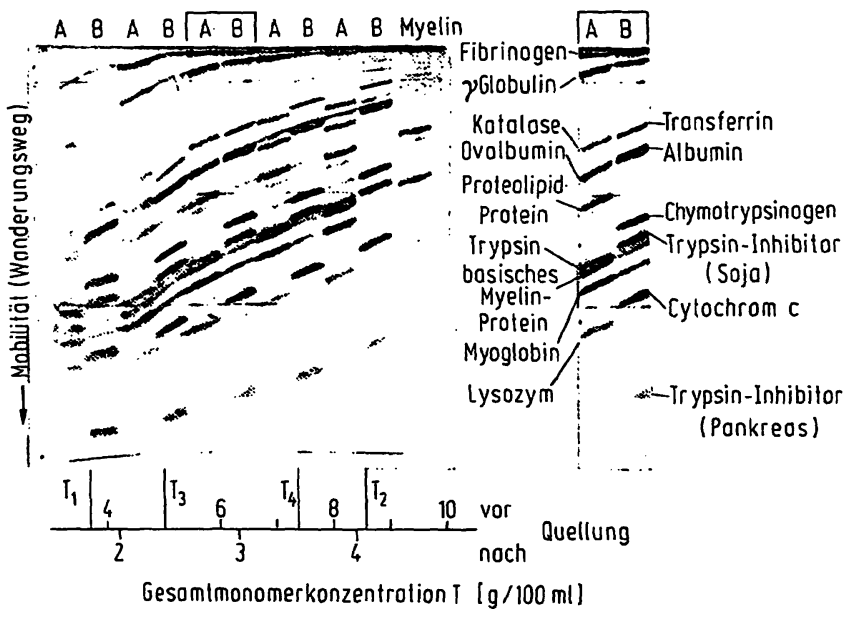

Abb. 10

Elektrophorese von Standardproteinen und Myelinmembranproteinen (s. Methoden) quer zu einem linearen Polyacrylamidgel-Konzentrationsgradienten in Phenol-Essigsäure-Wasser. Vernetzungsgrad $C=2$ Die zwei abwechselnd aufgetragenen Testmischungen $A$ und $B$ ent hielten die angegebenen Eiweißkomponenten (s. Methoden). Aus I. c. (5)

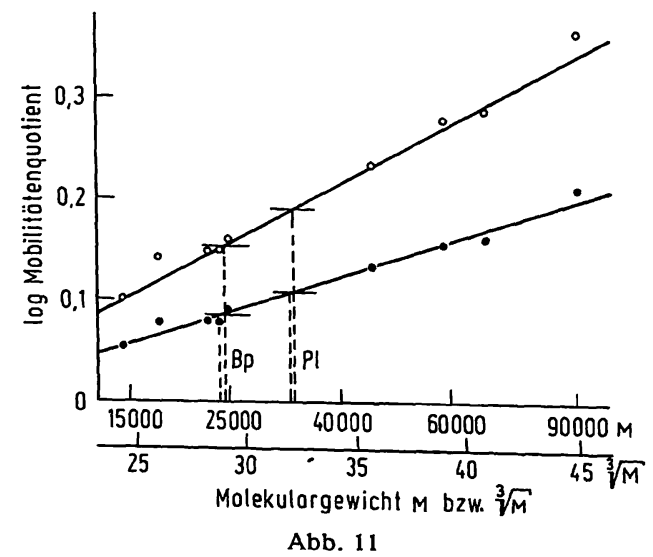

Linearer Zusammenhang zwischen dem Logarithmus des Mobilitätenquotienten und der dritten Wurzel aus dem Molekulargewicht bei entfalteten Polypeptidketten. Die Werte wurden gemessen aus Abb. 10 bei den Gelkonzentrationen $T_{1}$ und $T_{2}$ (Kreise) sowie $T_{3}$ und $T_{4}$ (Punkte). Aus den Schnittpunkten der erhaltenen Ordinatenwerte für die beiden Myelinproteine $(\mathrm{Bp}=$ Basisches Myelinprotein, Pl $=$ Pro-
teolipidprotein) mit den nach Methode der kleinsten Quadrate berechneten Näherungsgeraden ergaben sich aus beiden Meßreihen fast identische Molekulargewichte

3) Das „const“" bezeichnet Größen, welche nicht näher untersucht sind oder im jeweiligen Zusammenhang nicht interessieren. bildet eine systematische Ausnahme mit $+21 \%$. Es erschien legitim anzunehmen, daß sich auch Membranproteine in diesen Zusammenhang einfügen. Wir untersuchten die Eiweißkomponenten der Myelinmembran, die als Prototyp einer biologischen Membran gilt. Sie enthält wie bei den meisten Species, so auch beim Meerschweinchen, fast ausschließlich zwei Komponenten (Abb. 10, rechte Bande), das Basiscbe Myelinprotein (30) und das Proteolipid-Protein (31). In Abbildung 11 wurden die Molekulargewichte dieser Eiweiße aus ihren experimentell gewonnenen Mobilitätenquotienten graphisch bestimmt:

$$
\begin{array}{ll}
\text { Basisches Myelinprotein } .24500 \pm 10 \%, & \\
\text { Proteolipid-Protein } & 32800 \pm 10 \% .
\end{array}
$$

Die Richtigkeit dieser Werte ist gewährleistet unter der Voraussetzung, daß beide Proteine ein normales Wanderungsverhalten haben. Während die frühere Literatur 28000 als Durchschnittsmolekulargewicht für Myelinproteine (32) und 35-40000 als Molekulargewicht für das Basische Myelinprotein (33) angab, wurde neuerdings für das Basische Myelinprotein des Rindes aus dessen Aminosäurenzusammensetzung ein Molekulargewicht zwischen 15500 und 18200 errechnet (34). Eine Erklärung für das in diesem phenolischen System gegenüber wäßrigen Puffern ganż andersartige Wanderungsverhalten, wie es sich in den sehr verschiedenen Gleichungen (4) und (5) widerspiegeli, ist kaum in der exzessiven Gelquellung (Abb. 10) zu suchen. Vielmehr dürften die spezifischen Lösungsmittelkräfte die Proteinteilchen zu statistischen Knäueln entfalten, durch deren mögliche Deformierung der ganze Penetrationsmechanismus anderen Gesetzen unterliegt.

\section{Anwendungen}

Die Gleichungen (1)-(5) sind praktisch anwendbar zur Berechnung von Molekulargewichten aus gelelektrophoretischen Daten, zur Charakterisierung von bestimmten Proteinformen (Isoenzyme, Polymere)' und Vorausberechnung optimaler Trennbedingungen.

Prinzipiell kann nach Gleichung (4) das Molekulargewicht jedes Proteins aus dessen Mobilitätenquotienten direkt berechnet werden, wenn die Absolutwerte von $T_{1}, T_{2}, k_{c}$, a exakt bekannt sind. So lieferte Humanserum bei $\mathrm{T}_{1}=5$ und $\mathrm{T}_{2}=10(\mathrm{C}=2)$ für Transferrin die $R_{\mathrm{F}}$-Werte 0,543 und 0,197 , sowie für $\mathrm{Al}$ bumin die $R_{F}$-Werte 0,980 und 0,408 . Einsetzen von $\mathrm{k}_{\mathrm{C}=2}=5,2 \cdot 10^{-7}$ und $\mathrm{a}=0,046$ ergibt $\mathrm{z}: \mathrm{B}$. für das Molekulargewicht des Transferrin (Tra) die Zahlengleichung:

$$
\log 0,543 / 0,197=\left(5,2 \cdot 10^{-7} \mathrm{M}_{\mathrm{Tra}}+0,046\right) \cdot(10-5) .
$$

Es errechnet sich: $M_{\text {Tra }}=8 \dot{2} 700$ und entsprechend für Albumin (Alb): $M_{\text {Alb }}=59600$. Beide Werte liegen um rund $10 \%$ unter den echten Molekulargewichten der beiden Proteine. In der Tat hängt die Exaktheit einer solchen Direktberechnung von der Präzision des Versuchsansatzes und der Reproduzierbarkeit der Methode ab. Unvollständige Polymerisation, gealterte Reagenzien, verschiedene Feldstärken (bei Messung der 
Wanderungswege d) führen zu Diskrepanzen zwischen den im Experiment verwirklichten Realwerten von $T_{1}, T_{2}, k_{C}$, a und ihren in die Gleichung eingesetzten Idealwerten. Zur Ausschaltung dieser Fehlermöglichkeiten wird Gleichung (4) folgendermaßen vereinfacht:

(6)

$$
\log \mathrm{m}_{\mathbf{1}} / \mathrm{m}_{\mathbf{2}}=\text { const } \cdot \mathrm{M}+\text { const. }
$$

Im Versuch wird das Testprotein (die Testproteine) simultan mit zwei Eichproteinen, die sich regulär verhalten müssen, elektrophoriert. Dreimaliges Ansetzen von Gleichung (6) für die beiden Eichproteine und das Testprotein liefert nach Eliminieren der beiden Konstanten in Gleichung (6) eine Gleichung für das unbekannte Molekulargewicht. Ein Rechenbeispiel (Tab. 1) soll dies illustrieren. Transferrin und Oval-

Tab. 1

Rechenbeispiel. Bestimmung des Molekulargewichts von Hämoglobin. Eichsubstanzen Transferrin und Ovalbumin. Wanderungsweg $\mathrm{d}(\mathrm{mm})$ Eichsubstanzen Transferrin und Ovalbumin. Wanderungsweg d (mm)

\begin{tabular}{|c|c|c|c|c|c|c|}
\hline \multirow[t]{2}{*}{ Protein } & \multicolumn{2}{|c|}{$\begin{array}{l}4 \text { proz. } \\
\text { Gel }\end{array}$} & \multicolumn{2}{|c|}{12 proz. } & \multirow{2}{*}{$\begin{array}{c}\log d_{1} / d_{2} \\
\left(\log m_{1} / m_{3}\right)\end{array}$} & \multirow{2}{*}{$\begin{array}{l}\text { Molekular- } \\
\text { gewicht }\end{array}$} \\
\hline & $d_{1}$ & $\log d_{1}$ & $d_{2}$ & $\log d_{2}$ & & \\
\hline Transferrin & 110 & 2,041 & 17 & 1,230 & 0,811 & 90000 \\
\hline Ovalbumin & 240 & 2,380 & 68 & 1,833 & 0,547 & 45000 \\
\hline Hämoglobin & 131 & 2,117 & 29 & 1,462 & 0,655 & $?$ \\
\hline
\end{tabular}

bumin sind die Eichsubstanzen und das Molekulargewicht des Hämoglobins sei gesucht (Daten von ZivaAN (9)).

Es ergeben sich gemäß Gleichung (6) die drei Zahlengleichungen:

$$
\begin{aligned}
& 0,811=\text { const } \cdot 90000+\text { const } \\
& 0,547=\text { const } \cdot 45000+\text { const } \\
& 0,655=\text { const } \cdot M_{\text {Hb }}+\text { const. }
\end{aligned}
$$

Daraus errechnet sich das Molekulargewicht des Hämoglobins zu 63400.

Zwei Spezialfälle sollen nur kurz gestreift werden Finden sich für zwei oder mehrere Proteinbanden gleiche Steigungskonstanten K (Gleichung (3)) bzw. gleiche Mobilitätenquotienten (Gleichung (4)), so kann dies ein Indiz dafür sein, daß multiple Formen eines Proteins vorliegen, z. B. Isoenzyme. Diese Kriterien sind prinzipiell schon früher ohne Kenntnis irgendwelcher Gleichungen angewandt worden $(4,9,25)$. Findet sich dagegen für mehrere Banden eine regelmäßige Zunahme der Steigungskonstanten $K$ (Abb. 4) oder des Mobilitätenquotienten (Abb. 7), so kann dies ein Indiz dafür sein, daß polymere Formen eines Proteins vorliegen $(4,9)$.

Abbildung $3 \mathrm{mit}$ ihren vielfach sich überschneidenden Kurven zeigt beispielhaft, wie sehr die Trennbarkeit irgend zweier Komponenten, gegeben als ihr gegenseitiger Abstand, von der Auswahl der optimalen Gelkonzentration $\mathrm{T}$ abhängt. Aus den hergestellten Gelgradienten lassen sich die besser und die weniger geeigneten Gelkonzentrationen gezielt herauslesen und gegebenenfalls verwirklichen. Zum Beispiel wäre $T=8$ deshalb ungünstig, weil dort sowohl Apoferritin und Fibrinogen, als auch Katalase und Myoglobin je zu einer Bande verschmelzen. Soll die recht schwierige Fertigung von Gelgradienten vermieden werden, so wird aber auch mittels der aus Abbildung 3 gewonnenen Abbildung 5 eine geeignete Gelkonzentration gefunden. Nach Kenntnis der hier aufgeführten $\mathrm{Zu}-$ sammenhänge erhält man Abbildung 5 einfach und schnell in folgender Weise. Das Testgemisch wird z. B. bei $T=7$ und $T=10$ elektrophoriert, die Logarithmen der gemessenen Mobilitäten werden entsprechend Abbildung 5 gegen $T_{1}$ und $T_{2}$ aufgetragen und durch die jeweils korrespondierenden Meßpunkte Geraden gezogen, wobei die Bandenzuordnung in beiden Gelen bekannt sein muß. Analog verfährt man mit unbekannten Proben. Dieses gezielte Vorgehen ist besonders wertvoll bei Trennungen im präparativen Maßstab, wo Spuren einer Verunreinigung die biologische Aktivität einer Fraktion erheblich beeinträchtigen können.

\section{Diskussion}

Die hier aufgeführten empirischen Zusammenhänge werden zum überwiegenden Teil gut durch die Ergebnisse anderer Autoren gestützt $(4,8,10,21)$. Mit gewissen anderen Arbeiten besteht aber zunächst keine Übereinstimmung $(9,22,23)$. Eine von ZwaAN (9) vorgeschlagene Näherungsformel lautet unter $\mathrm{Ge}$ brauch der hier bevorzugten Terminologie sinngemäß:

$$
\log M=m_{2} / m_{1} \cdot \text { const }+ \text { const, }
$$

wo $m_{2} / m_{1}$ nach ZWAAN als „Retardationsquotient“ bezeichnet wird. Definitionsgemäß ist diese Größe umgekehrt proportional zum obigen Mobilitätenquotienten. Daraus wi rden alle Werte von ZwAAN rückgerechnet und entsprechend Gleichung (4) umgezeichnet. So wurde beispielsweise Abbildung 7 gewonnen. Sie beweist, daß die Messungen von ZwaAN genausogut zur Stützung von Gleichung (4) dienen können, so $\mathrm{da} ß$ die eigentliche Differenz zu diesem Autor nur in der Interpretation an sich gleicher Versuchsergebnisse durch eine empirische Näherungsfunktion besteht. Weiterhin wurden von TomBs (22) eine Gleichung

$$
\mathrm{M}=\mathrm{const} / \mathrm{T}_{0,5^{3}}
$$

und von INGram (23) eine Gleichung

$$
2 \mathrm{r}=\text { const } / \mathrm{T}_{0,5}+\text { const }
$$

vorgeschlagen, wo $T_{0,5}$ die Gelkonzentration symbolisiert, welche notwendig ist, um die freie Mobilität $m_{0}$ eines Teilchens auf ihren Halbwert zu reduzieren. Setzt man entsprechend in Gleichung (3) $\mathrm{T}=\mathrm{T}_{0,5}$ und $\mathrm{m} / \mathrm{m}_{0}=1 / 2$, so ergibt sich durch Auflösen nach $M$ jedoch die Aussage, daß $M$ eine lineare Funktion des Reziprokwertes von $T_{0,5}$ sein sollte, was sich mit den Gleichungen von TOMBS und INGRAM nicht verträgt. $\mathrm{Da}$ letzterer seine Messungen bei $\mathrm{pH}$ 2,2 durchführte und seine Gleichung eher mit Gleichung (5) korrelieren würde, ist es denkbar, daß die Proteine in seinem Puffersystem ähnliche Konformationsänderungen erfahren haben, wie in dem hier verwendeten phenolischen System $(\mathrm{pH} 2,0)$. Diese zitierten und 
andere Arbeiten (4, 5, 6, 25, 26), welche bisher die Möglichkeit der Molekulargewichtsbestimmung mittels Polyacrylamidgelelektrophorese wahrgenommen haben, fußen auf einem gemeinsamen Prinzip insofern, als die Elektrophorese in zwei oder mehr Gelen verschiedener Konzentrationen durchgeführt und ein geeigneter Wert gebildet wird, in dem die Effektivladung völlig eliminiert ist. Auch andere Methoden wurden vorgeschlagen. So arbeiteten Shapiro $(35,36)$ und andere $(37,38)$ mit Natriumdodecylsulfat enthaltenden Puffern, in denen dieses Detergens mit den Proteinen Komplexe eingehen soll, wodurch die Ladungen einander angeglichen werden. Dieses eindimensionale Elektrophoreseverfahren funktioniert vielleicht etwas schneller als $z$ weidimensionale, jedoch ist der Ladungseinflu $\beta$ möglicherweise nicht immer völlig ausgeschaltet. Außerdem werden die biologischen Eigenschaften der Testsubstanzen zerstört. Neuerdings wurde ein Zusammenhang $z$ wischen den Molekulargewichten und den in Richtung eines linearen Polyacrylamidgelgradienten zurückgelegten Wanderungswegen gefunden (39). Eine Reihe weiterer Arbeiten behandelt die gelelektrophoretische Bestimmung von Molekulargewichten von Nucleinsäuren. Diese finden sich gesammelt bei MAURER $(12,13)$.

Da sowohl Gelelektrophorese als auch Gelchromatographie den Molekularsiebeffekt von Gelen ausschöpfen, sind gewisse Parallelen in beiden Techniken zu erwarten. So hat MORris (8) eine ausgezeichnete Korrelation zwischen der Retardationskonstanten $\mathrm{K}$ der Gelelektrophorese und dem in der Gelchromatographie gebräuchlichen Verteilungskoeffizienten $\mathrm{K}_{\mathrm{AV}}$ nachgewiesen. Neuerdings existiert sogar eine einheitliche Theorie für Gelelektrophorese und Gelchromatographie (10). Da beide Techniken das Molekulargewicht indirekt über die Molekülgröße messen $(8,9,10)$, ist zu erwarten, daß die Ergebnisse durch Faktoren wie Dichte, Form, Gehalt an Kohlenhydraten, Lipoiden und prosthetischen Gruppen in gleichem Maße mitbestimmt, aber auch verfälscht werden. ANDrewv (40) hat dies bei der Gelchromatographie untersucht. Zwar kann man die Genauigkeit der Molekulargewichtsbestimmung mittels Polyacrylamidgelelektrophorese grob auf $\pm 10 \%$ veranschlagen $(4,35,36,37)$, im Einzelfall sind jedoch mögliche Überschreitungen nicht vorhersehbar. Zum Beispiel scheint die prosthetische Gruppe der Katalase eine dichtere Packung der Polypeptidkette zu bewirken, demgemäß verhält sie sich hier (Abb. 4) wie in der Gelchromatographie (40) wie ein Teilchen des Molekulargewichts 195000. Für Apoferritin existieren widersprüchliche Angaben, einmal soll es sich wie das sehr dichte Ferritin verhalten $(4,41)$, was auch Abbildung 4 nahelegt, zum anderen werden normale Werte gefunden (40). In der Apoferritinfraktion ist allerdings noch eine zweite Komponente vertreten (Abb. 3, unidentifiziertes Protein), deren Wanderung dem Erwartungswert für Apoferritin gut entspricht. Kohlenhydrathaltige Eiweiße spiegeln meist überhöhte Molekulargewichte vor (40). So er- mittelt die Gelchromatographie für das Ovomucoid $(\mathrm{M}=28000)$ mit einem Kohlenhydratanteil von 21 bis $27 \%$ ein Molekulargewicht von 55000 (40), analog lassen die gelelektrophoretischen Daten (8) auf ein Molekulargewicht von' $45-55000$ schließen. Ein Einfluß der Molekülform ließ sich bisher nur beim langgestreckten Fibrinogen signifikant nachweisen, für das die Gelchromatographie ein Molekulargewicht von 730000 bestimmt (40). Nach den hier erzielten Ergebnissen verhält sich Fibrinogen insofern eigentümlich, als bereits Gleichung (1) nicht zu gelten scheint. In Abbildung 5 ist deshalb für dieses Protein eine Ausgleichskurve eingezeichnet. Demnach kann höchstens ein Durchschnittsmolekulargewicht etwa bei 90000 angegeben werden. $\mathrm{Da}$ das tatsächliche Molekulargewicht des Fibrinogens bei 340000 liegt, deuten diese widersprüchlichen Befunde möglicherweise darauf hin, daß eine langgestreckte Molekülform das gelelektrophoretische und das gelchromatographische Verhalten in gegensätzlichen Richtungen beeinflussen könnte. Nebenbei sei angemerkt, daß die gelelektrophoretisch gewonnenen Molekulargewichte in Abhängigkeit von $\mathrm{pH}$ und Ionenstärke etwas variieren können $(4,8,10)$. Dabei ist noch offen, ob diese Schwankungen zufällig oder als Folge $\mathrm{pH}$ - oder ionenstärkeabhängiger Konformationsänderungen auftreten. Alle diese Störfaktoren sollten sich dann weitgehend ausschalten lassen, wenn die Polypeptidketten durch Anwendung dissoziierender Solventien zu statistischen Knäueln entfaltet werden. In dem verwendeten Phenolsystem z. B. verhält sich die Katalase-Untereinheit normal, auch Fibrinogen wandert qualitativ richtig (Abb. 10). Andererseits lag das Myoglobin in wiederholten Bestimmungen um $21 \%$ über dem Sollwert, wobei die farbtragende prosthetische Gruppe offensichtlich nicht vom Proteinanteil abgespalten wird. Dies mag darauf hinweisen, daß nicht immer eine ideale Entfaltung der Polypeptidkette erreicht wird.

Wie in den Molekulargewichtsberechnungen gezeigt wurde, sind die beiden eingeführten Konstanten a und $k_{c}$ praktisch brauchbare Größen, gleichgültig, ob die angegebenen Formeln auch für Molekulargewichte unterhalb 17800 gelten, was noch überprüft werden muß. Die bei verschiedenen Vernetzungsgraden gefundenen, fast identischen Werte für $\mathrm{a}=0,046$ (diese Arbeit: $C=2$ ) und $a=0,045$ (Hedrick (4): $C=3,3$ ) deuten an, $d a ß$ a tatsächlich eine von $C$ unabhängige Konstante ist. Sie besagt, daß alle Teilchen noch stärker als nach dem durch $k_{c} \cdot M \cdot T$ ausgedrückten Molekularsiebeffekt zu erwarten retardiert werden. Diese zusätzliche Retardation durch steigende Gelkonzentration zeigt sich im Experiment besonders klar an Molekülen, die so klein sind, daß für sie kein Siebeffekt im obigen Sinne meht in Frage kommt, z. B. an der Mobilităt von Farbstoffen wie Bromphenolblau $(M=670)$. Man hat versucht, diesen Effekt durch die Abnahme des frei verfügbaren Raumes (9) oder den endlichen Radius der Gelfäden (10) zu erklären, jedoch scheinen noch mehr und genauere Informationen über 
das Wanderungsverhalten niedermolekularer Substanzen notwendig zu sein, um diese Frage schlüssig zu beantworten. Der Vernetzungskoeffizient $\mathrm{k}_{\mathrm{c}}$ berücksichtigt die starke Abhängigkeit der Mobilität vom Vernetzungsgrad. Seine Definition, wie sie hier gehandhabt wurde, ist dann gerechtfertigt, wenn die angeführten Gleichungen für verschiedene Vernetzungsgrade gleichermaßen gültig sind. In der Tat passen die Gleichungen für Daten bei $C=5(9), C=3,3$ (4) und $\mathrm{C}=2$ (diese Arbeit). Orientierende Messungen an Gelen mit $C=0,5$ machen die Validität der Formeln selbst für diesen niederen Wert wahrscheinlich. Demnach verhalten sich Gele mindestens im Bereich $C=0,5$ bis $C=5$ insofern qualitativ gleichartig, als der Beitrag des Moleküls zum Siebeffekt, dessen Gesamtgröße durch das Produkt $k_{\mathrm{c}} \cdot \mathrm{M} \cdot \mathrm{T}$ beschrieben ist, vom Molekülvolumen (proportional $\mathrm{M}$ ) bestimmt wird. Demgegenüber vertreten andere (10) aufgrund rein theoretischer Überlegungen die Auffassung, daß Gele relativ niedrigen Vernetzungsgrades (bis $C=5$ ) (long fiber gels) die Teilchen mehr nach der molekularen Oberfläche, solche höheren Vernetzungsgrades (short fiber gels) mehr nach dem Molekülvolumen sieben. Nach Meinung des Autors erklärt dies nur unzureichend den starken Einfluß des Vernetzungsgrades, dessen korrekte theoretische Auslegung deshalb zum Prüfstein jeder entwickelten Theorie werden kann. Da Vernetzungsgrade über $C=5$ für die Praxis keine Vorteile bieten, wurden solche Werte hier nicht untersucht. Jedoch verdient ein Befund von HJERTEN (29) Beachtung, wonach bei Steigerung des Vernetzungsgrades über $\mathrm{C}=5$ die Mobilitäten wieder zunehmen. Demnach würden Gele dieses Vernetzungsgrades immer den für die jeweilige Gelkonzentration größtmöglichen Molekularsiebeffekt erzielen. Ein überraschend analoges Ergebnis wurde auch in der Gelchromatographie $(8,27)$ erhalten.

$\mathrm{Da}$ die Polyacrylamidgele aus hochgereinigten Chemikalien synthetisiert werden, wird der Polyacrylamidgelelektrophorese eine hohe Reproduzierbarkeit nachgesagt. Eine kritische Durchsicht der Literatur ergibt jedoch, daß erstens in ein und demselben Laboratorium oft schon eine Streuung auftritt, und $\mathrm{da} ß$ zweitens die Ergebnisse verschiedener Laboratorien kaum miteinander vergleichbar sind. Um die reproduzierbare Konstanz der Gelkonzentration T und des Vernetzungsgrades C, welche die Mobilitäten so entscheidend bestimmen, immer zu garantieren, müssen die Ausgangssubstanzen $z u$ jedem Zeitpunkt voll reaktiv sein. Dies soll ab und zu mittels geeigneter Tests, wie sie MAURER $(12,13)$ zusammengestellt hat, überprüft werden. So wird z.B. der Vernetzer „Bis“ wegen der geringen benötigten Mengen 20 bis $100 \mathrm{mal}$ langsamer als das Acrylamid im Labor umgesetzt und kommt teilweise erst nach Jahren, durch Spontanpolymerisation erheblich beeinträchtigt, zur Anwendung. Die Reproduzierbarkeit leidet auch dann, wenn die jeweiligen Polymerisationsbedingungen (saurer pH-Wert, Sauerstoffzutritt, Photopolymerisation) nur eine teilweise
Polymerisation zuließen. Für die Vollständigkeit der Polymerisation gibt es noch keinen Test, man kann aber einen solchen auf dem Molekularsiebeffekt des Gels aufbauen. Wenn nämlich einmal die Vernetzungskoeffizienten $k_{\mathrm{c}}$ für verschiedene Vernetzungsgrade unter Idealbedingungen verbindlich festgestellt worden sind, so können diese in jedem Labor nachbestimmt werden. Liegen die gefundenen Werte unter den Richtwerten, so weist dies auf gealterte Reagenzien oder unzureichende Polymerisationsbedingungen oder beides hin. Wesentlich ist außerdem, daß sich Gele, welche vor der Elektrophorese gequollen waren, zumindest quantitativ anders verhalten, als ungequollene Gele. Aus den von Morris (8) an gequollenen Gelen erzielten Ergebnissen lassen sich nämlich $\mathrm{k}_{\mathrm{c}}$-Werte berechnen, die ungefähr das 1,5fache der hier für ungequollene Gele gefundenen Werte ausmachen. Eine strikte Kontrolle all dieser kritischen Faktoren sollte die Reproduzierbarkeit der Polyacrylamidgelelektrophorese wesentlich verbessern und so eine Standardisierung für die klinische Diagnostik erleichtern. Auch in der Stärkegelelektrophorese wird eine unkontrollierbare, unerklärliche Schwankung der Mobilitäten beobachtet $(20,21)$. Aus der chemischen Struktur des Stärkemoleküls ergibt sich ein Vernetzungsgrad von etwa $4 \%$ (42). Dieser Wert mag je nach Herkunft des Naturproduktes Stärke variieren und so die unterschiedliche „Porosität" (21) verschiedener Stärkechargen erklären.

Obwohl die hier aufgezeigten Ergebnisse sowie deren Interpretation rein empirisch sind, dürfte sich möglicherweise auch eine theoretische Grundlage für die angegebenen Formeln finden. Physikalisch gesehen könnte z. B. das Produkt M.T eine Maßzahl für die Anzahl der Kollisionen zwischen Partikel und Gelfäden sein, während das Produkt $\mathrm{k}_{\mathrm{c}} \cdot \mathrm{M} \cdot \mathrm{T}$ ein $\mathrm{Maß}$ für den bei diesen Kollisionen vom Partikel auf das Gelnetzwerk abgeführten Impuls bilden würde, welcher sich mit steigendem Vernetzungsgrad durch Erhöhung der Interaktionswahrscheinlichkeit $z$ wischen den Gelketten vergrößern müßte. Diese skizzierte mehr dynamische Vorstellung über den Penetrationsmechanismus, welche auch den Vorstellungen anderer Autoren mehr entspräche $(43,44)$, soll bewußt eine Denkalternative zu den für Gelelektrophorese $(10,22,23)$ und Gelchromatographie postulierten statischen Theorien bieten, die in vielleicht etwas einseitiger Manier das Gel lediglich als starres Netzwerk betrachten, dessen Fäden von einem bewegten Teilchen nicht deplaciert werden können. Diese Gesichtspunkte werden in einer Monographie von MAURER (13) ausführlicher erörtert, welche auch alle anderen wesentlichen Informationen über die Polyacrylamidgelelektrophorese bringt.

Der Autor dankt den Herren Prof. Dr. H. Jarzkewrtz, Dr. E. MehL, Dr. H. R. Maurer und Dr. E. Hansert für nützliche Anrcgungen, Priv. Doz. Dr. O. Creutzrisldt und Dr. K. Zang für wohlwollende Fördcrung, sowie Frau EvA Mülsser für dic statistischen Berechnungen. 


\section{Literatur}

1. Smithies, O., Biochem. J. 61, 629 (1955). - 2. Raymond, S. und L. S. WenNTrAuB, Science, Washington 130, 711 (1959). - 3. Davrs, B. J. und L. Ornstein, A new high resolution electrophoresis method. Delivered at The Society for the Study of Blood at The New York Academy of Medicine, March 24, 1959. 4. HedRICK, J. L. und A. J. SMIth, Arch. Biochem. Biophysics 126, 155 (1968). - 5. Thorun, W. und E. MeHr, Biochim. biophysica Acta, Amsterdam 160, 132 (1968). - 6. Demus, H. und E. MEHL, Biochim. biophysica Acta, Amsterdam 203, 291 (1970). 7. HJertén, S., Arch. Biochem. Biophysics, Suppl. 1, 147 (1962). 8. Morris, C. J. O. R., Prot. Biol. Fluids, 14, 543 (1967). 9. Zwaan, J., Analytic. Biochem. 21, 155 (1967). - 10. Rodbard D. und A. Chranibach, Proc. Natl. Acad. Sc. USA 65, 970 (1970). - 11. HANNIG, K., Eine Neuentwicklung der trägerfreien Ablenkungselektrophorese und ihre Anwendung auf cytologische Probleme, Habilitationsschrift, München (1964). - 12. Maurer, H. R., Disk-Elektrophorese, Theorie und Praxis der diskontinuierlichen Polyacrylamidgel-Elektrophorese, Walter de Gruyter \& Co., Berlin (1968). - 13. MAURER, H. R., Disc-Electrophoresis and Related Techniques of Polyacrylamidegel Electrophoresis, 2nd edition, Walter de Gruyter \& Co., Berlin 1970 (in press). 14. Autrlio, L. A., W. T. Norton und R. D. Terry, J. Neurochem. 11, 17 (1964). - 15. Davrs, B. J., Ann. N. Y. Acad. Sci. 121, 404 (1964); - 16. Margolis, J. und K. G. KenRICK, Nature London 214, 1334 (1967). - 17. Slater, G. G., Fed. Proc. 24 225 (1965). - 18. Mert, E., Proc. Intern. Symp. on Metabolism of Nucleic Acids and Proteins and the Function of the Neuron, Castle Liblice, Excerpta Medica Foundation, Amsterdam (May 1967). - 19. Work, T. S., J. molec. Biol. 10, 544 (1964). - 20. Sirrthres, O., Arch. Biochem. Biophysics, Suppl. 1, 125 (1962). 21. Ferguson, K. A., Metabolism 13, 21 (1964). - 22. Tombs, M. P., Analytic. Biochem. 13, 121 (1965). - 23. INGRAM, L., M.
P. Tombs und A. Hurst, Analytic. Biochem. 20, 24 (1967). 24. Ornstern, L., Ann. N. Y. Acad. Sci. 121, 321 (1964). 25. Raymond, S., Ann. N. Y. Acad. Sci. 121, 350 (1964). - 26. Holmes, R., Biochim. biophysica Acta, Amsterdam 133, 174 (1967). - 27. FAwCETT, J. S. und C. J. Q. R. MorRIs, Separation Sci. 1, 9 (1966). - 28. ZwISLER, O. und H. BieL, diese Z. 4, 58 (1966). - 29. HJertén, S., S. Jerstedt und A. Trselius, Analytic Biochem. 27, 108 (1969). - 30. LAatsch, R. H., M. W. Kres, S. Gordon und E. C. Alvord, Jr., J. exper. Med. 155, 777 (1962). 31. Autilio, L., Fed. Prot. 25, 764 (1966). - 32. GeNt, W. L. G., N. A. Gregson, D. B. Gammack und J. H. Raper, Nature, London 204, 553 (1964). - 33. KIEs, M. W., C. J. BIER, E. C. Alvord, J. KaKu und S. Hruby, Fed. Proc. 25, 791 (1966). 34. Erlar, E. H. und M. Thompson, Arch. Biochem. Biophysics 129, 468 (1969). - 35. Shapiro, A. L., E. Viñuela und J. V. MaIzer, Biochem. Biophys. Res. Commun. 28, 815 (1967). 36. Shapiro, A. L. und J. V. Matzer, Analytic. Biochem. 29, 505 (1969). - 37. Weber, K. und M. Osborn, J. biol. Chemisrty 244, 4406 (1969). - 38. Dunker, A. K. und R. R. RUECKRRt, J. biol. Chemistry 244, 5074 (1969). - 39. KopperschläGER, G., W. Diezel, B. Brerwagen und E. Hofmann, FEBS Letters 5, 221 (1969). - 40. Andrews, P., Prot. Biol. Fluids, 14, 573 (1967). 41. ANDREws, P., Biochem. J. 96, 595 (1965). - 42. KarLson, P., Biochemie, Georg Thieme Verlag, Stuttgart (1964). - 43. TsanEv, R., D. Staynow, L. Kokileva und I. Mradenova, Analytic. Biochem. 30, 66 (1969). - 44. GoRdON, A.H., Electrophoresis of Proteins in Polyacrylamide and Starch Gels, North Holland Publ. Co., Amsterdam-London (1969), p. 15. - 45. Williams, D. E. und R. A. Rerspeld, Ann. N. Y. Acad. Sci. 121, 373 (1964). 46. Laurent, T. C. und H. Persson, Biochem. biophysica Acta, Amsterdam 78, 360 (1963).
Wolfgang Thorun 8000 München 23 Kraepelinstr. 2 